\title{
Imagens endógenas e imaginação simbólica
}

\section{Endogenous images and symbolic imaginati}

\author{
Malena Segura Contrera \\ Pós-doutorado na Universidade Federal do Rio de Janeiro, Doutora em Comunicação e Semiótica pela Pontifícia Universidade \\ Católica de São Paulo (2001), especialista e terapeuta em Psicologia Junguiana e Professora do Programa de Pós-graduação da \\ Universidade Paulista (UNIP) \\ $<$ malenacontrera@uol.com.br>
}

\section{RESUMO}

O presente artigo trata do caráter endógeno da imagem, propondo que se considere as diferenças existentes entre imagem técnica e imagem simbólica e relacionando esta última aos processos do imaginário e da imaginação. Para além do interesse de propor uma classificação da imagem, o que se afigura claramente como um projeto inglório, o objetivo da reflexão é chamar a atenção para a dimensão imaginária presente na imagem simbólica, compreendendo imagem como agente de alteração no campo da energia psíquica. Valendo-se dos estudos da imagem, realizados por Hans Belting, E. Morin, G. Durand, C. G. Jung, J. Hillman e demais autores que se debruçaram sobre o tema da imagem simbólica e da imaginação, a presente reflexão, ainda que seja um pequeno passo frente a um longo caminho que se insinua, representa a intenção de propor uma abordagem teórica que considere a integração entre os temas da imagem, do imaginário e da imaginação.

\section{ABSTRACT}

This paper deals with the endogenous character of the image, proposing that is considered the differences between technical and symbolic image linking the latter to the processes of the imaginary and imagination. Beyond the interest to propose a classification of the image, which appears clearly as an inglorious project, the goal of the discussion is to draw attention to the imaginary dimension present in symbolic image comprising image as an agent of change in the field of psychic energy. Using image studies conducted by Hans Belting, E. Morin, G. Durand, C. G. Jung, J. Hillman and others researchers who pored over the topic of symbolic image and imagination, this reflection, even if it is a small step in front of a long path that insinuates itself, represents the intention to propose a theoretical approach that considers the integration between the subjects of the image, of the imaginary and imagination.

Keywords: Symbolic image. Imagery. Imagination.

\section{Introdução}

O tema da imagem apresenta desafios só possíveis de serem avaliados na medida em que nos debruçamos sobre ele. Em parte, por conta da própria natureza complexa da imagem, em parte por conta da impossibilidade de separá-la simplesmente dos processos do imaginação e do imaginário. O que temos visto na maior parte das pesquisas acerca da imagem é que se tem considerado apenas as condições técnicas de sua produção. Sem dúvida esse enfoque é de enorme importância, especialmente se avaliamos a centralidade das tecnologias de produção e de recepção de imagens no contexto pósindustrial do mundo contemporâneo. Relevantes reflexões sobre sua natureza 
técnica têm sido inspiradas pelas contribuições dos estudos semióticos, dos estudos sobre fotografia, sobre cinema, sobre as teorias da materialidade, e especialmente sobre a perspectiva histórica e cultural da natureza tecnológica da comunicação contemporânea.

Há, no entanto, bem menos reflexões que tratem do caráter endógeno da imagem e de suas relações com a imaginação e com o imaginário. É nesse aspecto que quero insistir, mesmo sabendo que provavelmente uma das razões da raridade de tais reflexões atuais a esse respeito seja a natureza inabarcável do tema, a profunda dificuldade de precisão científica quando adentramos a imagem, quando buscamos por seus aspectos intangíveis. Como quem procura pelo Proteu mítico, nos vemos perdidos no meio de um mar, agarrados a um monstro marinho que se metamorfoseia e que só depois de muito tempo, se resistirmos, revela-se o sábio, o oráculo que nos responderá o que queremos saber. Quase sempre nos afogamos antes, e talvez comigo não seja muito diferente e esse texto seja uma carta de afogada, numa garrafa jogada ao mar.

De qualquer maneira, o que segue me intrigando, pós-afogada ou não, é o caráter endógeno da imagem e suas relações com os imaginários cultural e mediático.

A presente reflexão se ocupa justamente dessa tentativa de organizar um pouco os saberes acerca dessa relação e de problematizar a imagem a partir não apenas de seu status tecnológico ou aplicativo, mas, sobretudo, das formas de consciência que imaginam essa imagem, que a acolhem, desdobram ou apenas são atravessadas por ela, e do imaginário que desse processo possa brotar.

\section{Sobre imagens endógenas}

A contribuição de Hans Belting (2007) acerca da distinção entre imagens endógenas e exógenas, distinção na qual insistimos nos últimos anos ${ }^{1}$, é fundamental para situarmos essa complexa teia existente entre imagem e imaginário. Belting propõe que à representação sensível de uma imagem, partilhável, apresentada a partir de certo código escolhido na representação, corresponde uma cadeia de imagens internas, presentes não apenas na mente do indivíduo que as interpreta, mas, principalmente, na esfera da memória cultural.

1 Tratamos dessa distinção em Mediosfera (2010) e no artigo Na selva das imagens (2005). 
Apesar de que a parte sensível da imagem, aquela que se pode apreender por meio de algum dos sentidos humanos, em certa medida seja indissociável de sua dimensão intangível, há, porém, uma precedência da dimensão endógena da imagem, ou seja, a imagem já existe muito antes de tornar-se perceptível. Nesse ponto é preciso distinguir aqui as diferenças existentes entre a imagem simbólica e o que escolhemos chamar de imagens técnicas, seguindo a trilha de Vilém Flusser, conforme exporemos a seguir.

Não se trata aqui de estabelecer ou propor uma classificação, o que me parece sempre uma causa perdida já de saída quando tratamos dessa entidade oceânica que é a imagem, mas é preciso dizer que a maior parte das tentativas de compreender a imagem em si mesma parece ignorar a importância da relação entre a imagem e o tipo de consciência que a percebe e que a imagina.

Podemos usar um exemplo trivial para tornar mais claro o que tentamos dizer: a imagem visual da Virgem Maria para um devoto, por exemplo, não é a mesma que está frente a um aborígene, e não é a mesma que está sendo exibida estampada em uma camiseta na passarela de um desfile de moda. Mesmo sendo a mesma, não é a mesma, já que, enquanto segue sendo a mesma do ponto de vista visual e iconográfico (com algumas variações próprias do suporte), é muito diversa do ponto de vista do seu poder de evocação, de seu potencial imaginativo propriamente dito.

O ponto central aqui é que consideramos que seja necessário sempre compreender a imagem a partir de sua relação com a consciência imaginante em questão. Logo, a imagem pode ser mais bem compreendida a partir de dois processos que a geram, o da imagem enquanto potencialidade imaginária e a relação existente entre imagem e consciência imaginante. Mesmo sabendo da complexidade teórica que essa concepção abriga, vejo como incontornável tratar dos processos de consciência que imaginam essa imagem, e esse é um aspecto que vem me ocupando nos últimos anos na investigação dos temas da empatia, da mimese e da hipnogenia.

A discussão se alonga e por isso, no presente texto, atenho-me apenas à reflexão acerca da potencialidade imaginária da imagem, o que nos remete diretamente ao seu caráter endógeno. O caráter endógeno da imagem ainda tem de ser explorado e é muito mais do que seu mero significado. Falar de signo e significado, aliás, desloca a questão da natureza e da realidade da imagem e do imaginário para a discussão sobre os códigos, sobre os processos de linguagem, apagando a existência própria da imagem e o papel dos processos de consciência presentes na imaginação. Talvez nessa opção encontre-se, escondida, uma 
profunda fé (iluminista) na racionalidade humana e na possibilidade de pensar a vida a partir das operações cognitivas lógicas e racionais.

Mas essa não é minha opção, gosto das funduras dos reinos de Hermes e Hades, o que nos leva inevitavelmente aos fenômenos psíquicos, como bem sabia Aby Warburg, por experiência própria².

\section{Imagem e imaginário como fenômenos psíquicos}

A escola de Cornelius Castoriadis oferece-nos uma grande ferramenta para a compreensão de como as condições sociais e as práticas imaginativas que estas provocam, em alguns casos, definem a criação dos conteúdos dos imaginários locais, que nascem do diálogo com as condições concretas de vida: "toda sociedade é uma construção, uma constituição, uma criação de um mundo, de seu próprio mundo" (Castoriadis, 1965, p. 241). Ele, no entanto faz uma distinção entre "imaginário social" e "imaginação radical".

Acerca do que ele designou de imaginário social há muitas reflexões, mas pouco se falou sobre a "imaginação radical":

"Como social-histórico ele (imaginário) é o rio aberto do coletivo anônimo; como psiquê-soma ele é fluxo representativo/afetivo/ intencional. Aquilo que no social-histórico é posição, criação, fazer ser, nós o denominamos imaginário social, no sentido primeiro do termo, ou sociedade instituinte. Aquilo que na psiquê-soma é posição, criação, fazer ser para a psiquê-soma, nós o chamamos imaginação radical" (Castoriadis, 1965, p. 493).

Sua concepção de imaginário social, no entanto, guarda um problema, já que sua visão subentende que o imaginário seja um epifenômeno do social, situando a origem do imaginário nas condições sociais concretas de vida, considerando só uma direção do amplo processo de imbricação entre imaginário e sociedade. O problema aqui, pelo que me parece, não reside na lógica da proposição, mas no recorte temporal que se faz; considera-se as relações entre imaginário e sociedade historicamente, de forma linear, como se o imaginário se restringisse aos limites da memória histórica de uma sociedade. Nesse sentido, a proposição de Morin sobre os processos de recursividade

2 Refiro-me aqui ao diagnóstico de esquizofrenia que Aby Warburg recebeu e a seu período de 5 anos de internação, no qual ele teve de lidar muito intimamente com a natureza endógena e arquetípica da imagem, e do qual resultou seu brilhante texto "O ritual da serpente" (conferência proferida em 1923 e que depois seria publicada). Coincidentemente, o psiquiatra que dirigia a clínica na qual esteve Warburg era Ludwig Binswanger, que foi aluno de Jung. 
presentes na cultura e na criação dos imaginários propõe uma visão menos linear e causal e me parece bem mais adequada para tratar de compreender melhor a complexidade relativa ao tema.

Já a noção de imaginação radical de Castoriadis me parece bem mais instigante e menos sobre-determinada que a primeira, dialogando com a concepção de imaginário de autores que se ocuparam centralmente do tema, tais como Edgard Morin e Gilbert Durand, ou ainda de autores que trataram a questão das imagens simbólicas, como Mircea Eliade e Joseph Campbell. Todos (exceto Castoriadis), não por acaso, inspiraram-se na proposição de Carl Gustav Jung acerca do inconsciente coletivo para pensarem o imaginário como préexistente às condições sociais concretas de vida de uma sociedade específica.

Considerando a memória da espécie em si, como um ambiente imaginário no qual as sociedades se estabelecem, esses autores não acreditam em um a priori absoluto do imaginário, tendo clareza de que cada sociedade o reproduz, reatualiza e recria a partir de suas condições e particularidades, mas também não consideram o imaginário como um epifenômeno do social, levando em consideração a lei da cumulatividade da memória cultural da espécie. Há alguns universais, e ainda que com eles façamos o que bem quisermos, inclusive negá-los, eles estão aí no enorme paralelismo das mitologias comparadas, da literatura universal, da história das religiões, como sabem os que se atreveram por esses campos. Essas recorrências encantaram Aby Warburg, relacionam-se à pós-vida das imagens que habitam isso que Morin chamou de Noosfera e que, como este afirma, de forma ousada e ainda pouco compreendida, possui certa "autonomia relativa"3.

Imaginário não é epifenômeno do social, esse é o ponto que nos interessa aqui. Quem só considera a produção das imagens exógenas, confundindo a imagem com seu suporte e sua condição técnica de reprodução, pode afirmar que a imagem e o imaginário sejam epifenômenos do social. Quem olha para dentro, quem lida com o sonho, com o mito, não pode fazer isso sem cair em profundas contradições. É preciso considerar a natureza endógena da imagem e seu oceano etéreo, sua ancestralidade e sua natureza incerta que nos remetem ao que Carl Gustav Jung chamou de inconsciente coletivo, ao afirmar, em 1916, que: "o inconsciente coletivo compreende toda a vida psíquica dos antepassados, desde seus primórdios. É o pressuposto e a matriz de todos os fatos psíquicos..." (Jung, 1986, p. 48)

3 Tratei centralmente desta questão no livro Mediosfera, 2010.

4 Em outro momento, ele fala ainda que: "Temos de distinguir o inconsciente pessoal do inconsciente impessoal ou suprapessoal. Chamamos este último de inconsciente coletivo porque 
O próprio Jung tinha muita clareza acerca da relação entre imagem e psique, e essa relação é retomada centralmente pela obra de James Hillman, que baseia toda sua perspectiva de pensamento sobre a Psicologia na centralidade do imaginário e na importância da imaginação. Outro autor que reforça a importância da imagem e da imaginação nos estudos de Jung é Michael Vannoy Adams:

\footnotetext{
"'Todo processo psíquico', diz Jung, 'é uma imagem e um imaginar' (CW 11: 544, par. 889). Ele define o complexo como 'uma coleção de imaginações' (CW 2: 601, par. 1352). Ele diz que 'a psique consiste essencialmente de imagens' (CW 8: 325, par. 618) e que 'imagem é psique"' (CW 13: 50, par. 75) (Adams, 2008).
}

Ao convocarmos para o imaginário seu estatuto psíquico, estamos chamando a atenção para a natureza dos fenômenos psíquicos, que são, em primeira instância, fenômenos de energia.

Nesse sentido torna-se necessário compreender não apenas a importância do conceito de energia psíquica para a Psicologia, mas especificamente como a Psicologia Analítica de Jung vê a energia psíquica e como a considera fundamental para a compreensão dos fenômenos psíquicos, já que a visão de Jung difere bastante da de outras escolas da Psicologia:

Toda força e todo fenômeno são uma certa forma de energia. Forma é imagem e maneira de aparecer. Ela exprime duas coisas: primeiro, a energia que nela se manifesta, e segundo, o médium em que a energia aparece. Pode-se afirmar, por um lado, que a energia produz a sua própria imagem e, por outro lado, que o caráter do médium força a energia para dentro de uma determinada forma (Jung, 1989, p. 74).

Jung aproximou a discussão acerca da energia psíquica da imagem e do simbólico, divergindo bastante da interpretação de S. Freud sobre a libido. Buscando a integridade da imagem, considerando a relação de suas dimensões exógena e endógena, Jung via no símbolo o papel central para mobilização da energia psíquica, bem como a evidência de como essa energia se manifestava:

é desligado do inconsciente pessoal e por ser totalmente universal; e também porque seus conteúdos podem ser encontrados em toda parte, o que obviamente não é o caso dos conteúdos pessoais" (Jung, C. G., 2011, p. 77. Original: 1917). 
"o mecanismo psicológico que transforma a energia é o símbolo" (Jung, 1985, p. 44).

A dimensão endógena da imagem, quase sempre esquecida ou minimizada, ao juntar-se à sua evidência, sua materialidade, aponta justamente para a natureza psíquica integralizante da imagem, logo, sua realidade como portadora e mobilizadora de energia.

Nem toda imagem é simbólica

Fotografias não são imagens (James Hillman)

Ao falar sobre a imagem, Flusser (2011) atém-se quase que exclusivamente ao aspecto exógeno das imagens visuais, e toda sua bela reflexão sobre o tema coloca o código no centro do que interessa: as dimensões, a espacialidade, as superfícies; sua reflexão não privilegia a natureza endógena da imagem. Flusser tratou da imagem técnica ${ }^{5}$, uma categoria específica de imagem na qual a dimensão endógena, na melhor das hipóteses, fica em segundo plano, e que não contempla (ou considera) necessariamente o que Gilbert Durand chamou de caráter simbólico.

Quando Durand trata de imagem simbólica, é justamente desse núcleo germinador pré-figurativo da imagem que ele fala:

Não podendo figurar a infigurável transcendência, a imagem simbólica é transfiguração de uma representação concreta através de um sentido para sempre abstrato. O símbolo é, pois, uma representação que faz aparecer um sentido secreto, é a epifania de um mistério (Durand, 1993, p. 11-12).

A natureza simbólica de uma imagem a torna sempre inabarcável. Qualquer tentativa de reduzir a imagem simbólica à sua (possível) significação

5 A compreensão da natureza específica da imagem técnica se beneficia enormemente da clássica discussão benjaminiana acerca da obra de arte na era da reprodutibilidade técnica. Quando não há consciência agindo na produção da imagem, quando a imagem é produzida mecânica ou eletronicamente por um aparato que a reproduz vertiginosamente, sem escolher contextos, sem aproximá-la dos "melhores vizinhos" (para usar uma expressão de A. Warburg), essa imagem não será a mesma que em uma situação em que tudo isso ocorre. Esse aspecto da discussão aponta necessariamente para se pensar a relação entre imagem e consciência humana, aspecto que não ignoro e do qual tenho me ocupado, mas que extrapola o intuito do presente texto. 
e entendê-la como signo, sinal, é a destruição do próprio âmago dessa imagem, e esse intraduzível se deve ao propriamente simbólico, como entendido tanto pela escola de Durand, quanto pela de Jung ${ }^{6}$. Carlos Bernardi, da escola de Jung, expõe isso claramente:

\begin{abstract}
O símbolo deve ser mantido como enigma, algo que nunca será desvendado ou solucionado, que nunca será petrificado em significação... pela presença deste elemento desconhecido, o símbolo verdadeiro, que Jung denomina de símbolo vivo, não pode ser criado intencionalmente pelo homem, por sua consciência, mas é sempre um acontecimento, um evento cujo sentido não está presente, mas que se doa ou exige ser lido e compreendido em sua radical alteridade. Eles desejam que a consciência simplesmente os deixe acontecer (Bernardi, 2008).
\end{abstract}

Aparição, hierofania, epifania, revelação de algo nunca totalmente explicável ou compreensível pela consciência, pela razão, mistério ${ }^{7}$. Algo que faz aparecer um escondido, que faz emergir um submergido, Proteu saindo das águas do mar e fazendo sua revelação. Mas essa revelação não é portadora de um sentido racional, de um conteúdo que possa ser abarcado racionalmente. 0 que a imagem simbólica revela de fato é que houve uma alteração no campo da energia psíquica, que algo aconteceu, que um buraco na consciência comum se abriu e que por ele surgiu algo, como o raio de Zeus surgindo por entre as nuvens (e essa cena nos diz algo sobre a associação entre imagem e eletricidade).

Os efeitos que essa aparição possa surtir na consciência de quem vive esta experiência não se pode precisar, é totalmente imprevisível e deve ser compreendido caso a caso (muito embora Jung tenha tratado dos casos das psicoses coletivas, dos contágios psíquicos das massas como situações em que os efeitos de alguns símbolos apresentam uma similitude extraordinária, em cadeia $\left.^{8}\right)$.

6 Sobre isso Jung afirmou que: "a interpretação semiótica torna-se sem sentido quando é aplicada de modo exclusivo e sistemático, quando, em suma, ignora a natureza real do símbolo e o rebaixa à mera condição de sinal" (Jung, 1985, p. 44).

7 Arriscaria dizer que o mistério é o tema que liga definitivamente o tema da imagem ao tema da religião.

8 Essa discussão aparece em vários livros de Jung, podemos vê-la, por exemplo em Civilização em transição (2011), Aspectos do drama contemporâneo (1990) e Psicologia do Inconsciente (2011). 
Mas há algo comum, a imagem simbólica é portadora de energia, em contato com ela, somos afetados por algo, mesmo que não o saibamos conscientemente. Não deciframos, lemos ou interpretamos estrito senso a imagem simbólica, ela nos acontece. E quando nos acontece, ficamos a imaginar coisas, nos perdemos por entre brumas, alma adentro.

Hillman fala acerca das imagens que "elas são a psique na sua visibilidade imaginativa; como repertório primário, a imagem é irredutível" (Hillman, 1992, p. 27).

A arte-terapia tem abundantes estudos sobre o efeito da imagem simbólica e das práticas imaginativas na psique humana, e talvez os mais conhecidos no Brasil sejam os estudos de Nise da Silveira conservados pelo Museu de Imagens do Inconsciente do Rio de Janeiro?.

No entanto, é importante reiterar que nem toda imagem faz irromper um processo psíquico por meio da liberação de energia. As imagens técnicas, pelo contrário, roubam a energia, já que se alimentam do nosso olhar (no caso das imagens visuais), que vivem da nossa atenção, do nosso tempo de vida, como demonstrou Norval Baitello Junior ao falar sobre o fenômeno da iconofagia. Não por acaso as imagens mediáticas, em sua quase totalidade imagens técnicas, sucedem-se vertiginosamente, sem que tenhamos a menor chance de dedicar a alguma delas o tempo lento da imaginação. Sabemos bem como especialmente os meios eletrônicos se pautam pela dromologia (cf. Paul Virilio).

A imagem simbólica, pelo contrário, é portadora de uma enorme concentração de energia, ela é um vórtex que irradia energia psíquica, partindo da psique coletiva, enredando-nos numa teia invisível ancestral, arquetípica. $\mathrm{E}$ como é portadora de energia, ela provoca um desacomodamento, ela gera um acontecimento: a imaginação.

\section{O terceiro elemento: a imaginação}

Ouvi certa vez de Dietmar Kamper que frente ao poder do imaginário mediático estereotipador só mesmo a imaginação como antídoto. Desde então (lá se vão uns 17 anos) tenho feito minha lição de casa no intuito de entender

9 Além dos estudos de Nise da Silveira, destaca-se a pesquisa de Léo Navratil (1972) sobre o uso da arte-terapia com o tratamento de esquizofrênicos. 
mais profundamente o que isso poderia exatamente significar. O que entender exatamente por imaginação?

As pistas que me pareceram mais interessantes para uma quase-resposta a essa questão são as fornecidas pelos estudos da Psicologia Junguiana: a imaginação é o trabalho das imagens em nós, é o processo pelo qual, ao nos ocuparmos com as imagens, somos ocupados por elas.

A ilusão de achar que toda a direção do processo imaginativo parte apenas da consciência humana e que as imagens são apenas imaginadas passivamente é um mal do qual padecem, em geral, os estudos da Comunicação e da Mídia que tratam do imaginário, e poderia ser entendido como mais um aspecto do que Luigi Zoja (2000) chamou de História da Arrogância, ao tratar do pensamento científico ocidental moderno. Há uma sinergia entre imagem e consciência imaginante que não pode ser ignorada se se quiser caminhar para o fundo do tema da imaginação (e das imagens).

Dentre as diversas ramificações da escola pós-junguiana é James Hillman quem faz uma contribuição que considero decisiva para a compreensão do papel e da importância da imaginação e de suas relações com a imagem. Hillman é o proponente de uma ramificação da Psicologia Analítica de Jung que se chama, não por acaso, Psicologia Arquetípica, e sua abordagem psicológica aproxima definitivamente as teorias da imagem e do imaginário das práticas psíquicas de uma imaginação complexa que retoma o estatuto mítico do humano e a impossibilidade de pensar o humano fora de uma perspectiva imagética e arquetípica.

Essa perspectiva propõe uma indissociabilidade dos fenômenos da imagem, do imaginário e da imaginação. Estamos tratando de um processo em ação que ocorre, ao mesmo tempo, na alma individual, na alma da humanidade e na alma do mundo. Hillman, que dedicou praticamente sua vida à investigação desse tema, afirma que "uma imagem é dada pela perspectiva imaginativa e só pode ser percebida pelo ato de imaginar" (Hillman, 1992, p. 28).

A imaginação não tem em nosso tempo um status significativo, sobretudo por se tratar de um processo que requer tempo lento, languidez, espaços vazios na agenda e abismos abertos na alma. Não é produtiva, não pode ser quantificada, nem seus resultados podem ser avaliados concretamente; e, sobretudo, é perigosamente transformadora e não raras vezes nos faz resvalar desastrosamente em nossas sombras e em nosso próprio corpo. É um tema impopular na própria Psicologia, por que não o seria na área de Comunicação? Apenas a Arte a tem suportado, muito embora não raramente a trate como recurso técnico de produção. 
Mesmo assim, revirando esse grande incômodo e propondo resgatar a dimensão endógena da imagem como o que propriamente se refere à natureza dos processos imaginários e à possibilidade da imaginação criadora, a proposta deste texto foi convocar para a reflexão sobre imagem seu parentesco etimológico com os reinos da magia e da mágica, na contramão da crença de que a imagem é mero fruto da tecnologia (ou tecnofagia) que a produz.

Por fim (mas ainda a tempo de pontuar), ao focar na relação entre imagem simbólica, imaginário e imaginação, por certo não estou postulando que o caráter endógeno e exógeno da imagem esteja sempre dissociados, como já foi bastante discutido em outros momentos ${ }^{10}$. À presente reflexão deverá, por necessidade e rigor, se seguir a consideração atenta das relações existentes entre a dimensão exógena e endógena da imagem, e as consequências da dissociação dessas duas dimensões, da qual podemos indicar, como pós-texto, a perda da consciência hermética e do pensamento alquímico ${ }^{11}$. Mas esse é um fio para um outro (próximo) labirinto.

\section{Referências}

ADAMS, M. V.Hillman sozinho em busca da imaginação: A Psicologia do Bezerro de Ouro. In: Revista Rubedo - Revista de Psicologia Junguiana e Cultura. Rio de Janeiro, 2008. Disponívelo em: <http://www.rubedo.psc.br/artigosc/bezerro. htm>. Acesso em: 12 mar. 2015.

BAITELLO JR., N. A era da iconofagia. São Paulo: Hacker Ed., 2005.

. A maçã, a serpente e o holograma. S. Paulo: Ed. Paulus, 2010.

BAITELLO JR., N. e CONTRERA, M. S. Na selva das imagens - contribuições para uma arqueologia da imagem. Revista Significação. São Paulo, vol. 33, n. 25, 2006. Disponível em: <http://www.revistas.usp.br/significacao/article/view/65623>. Acesso em: 18 mar. 2015.

BELTING, H. Antropologia de la imagen. Madri: Katz Ed., 2007.

10 Refiro-me ao artigo Na selva da imagens, de N. Baitello Jr. e M. S. Contrera (2006) e ao livro Mediosfera (2010).

11 Aproximei-me dessa questão ao tratar do fenômeno do desencantamento do mundo, no livro Mediosfera, a partir da proposição de Morris Berman sobre as diversas formas de pensamento, especialmente o que ele diz acerca da mudança do pensamento hermético, pré-moderno, para o pensamento mecanicista (Berman, M. In: El reencantamiento del mundo, 1987). 
BERMAN, M. El reencantamiento del mundo. Chile: Ed. Cuatro Vientos, 1987.

BERNARDI, C. "O estatuto da imagem em Jung". Revista Rubedo - Revista de Psicologia Junguiana e Cultura, R. de Janeiro, 2008. Disponível em: <http://www.rubedo. psc.br/artigosb/estaimag.htm>. Acesso em: 10 abr. 2015.

CASTORIADIS, C. L'institution imaginaire de la societé. Paris: Seuil, 1965.

CONTRERA, M.S. Mediosfera - meios, imaginário e desencantamento do mundo. S. Paulo: Ed. Annablume, 2010.

Mediosphere and the crisis of sense. In: Filosofia da Mídia, v. VII. S. Petersburgo: Universidade de S. Petersburgo, 2011.

Emoção e imaginação - diferentes vínculos, diferentes imaginários. Revista Ghrebh. São Paulo, 2012. Disponível em: <www.cisc.org.br>. Acesso em: 15 abr. 2015.

Simpatia e Empatia - Mediosfera e Noosfera. In: BAITELLO e WULF. Emoção e imaginação - os sentidos e as imagens em movimento. S. Paulo: Estação das Letras e Cores, 2014.

DURAND, G. A imaginação simbólica. Lisboa: 70, 1995.

FLUSSER, V. Filosofia da caixa preta. São Paulo: Hucitec, 1985.

HILLMAN, J. Psicologia Arquetípica. S. Paulo: Cultrix, 1992.

O sonho e o mundo das trevas. Petrópolis: Vozes, 2013.

JUNG, C. G. A energia psíquica. Petrópolis: Vozes, 1985.

Símbolos da transformação. Petrópolis: Vozes, 1989.

Aspectos do drama contemporâneo. Petrópolis: Vozes, 1990.

Civilização em transição. Petrópolis: Vozes, 2011.

O eu e o inconsciente. Petrópolis: Vozes, 2011 a.

Psicologia do inconsciente. Petrópolis: Vozes, 2011 b.

MORIN, E. O método IV. Lisboa: Publ. Europa-América, 1988.

NAVRATIL, L. Esquizofrenia y Arte. Barcelona: Editorial Seix Barral, 1972.

WARBURG, A. El ritual de la serpiente. México: Sextopiso Editorial, 2004.

ZOJA, L. História da arrogância. São Paulo: Axis Mundi, 2000. 
Recebido em: 15/07/2015

Aceito em: 04/08/2015

Endereço da autora:

Malena Segura Contrera <malenacontrera@uol.com.br>

Programa de Pós-graduação da Universidade Paulista (UNIP).

Av. Paulista, 900

São Paulo, SP - Brasi

Fone: (11) 0800109000 